\title{
Contemporary Strategic Approaches for Social Value Creation based on Dimensions of Organizational Performance
}

\author{
Kate Trajkova*, Marko Andonov, Zoran Mihajloski, Marija Kojchevska
}

School of law, University American College Skopje, Macedonia

Copyright $\mathrm{O} 2018$ by authors, all rights reserved. Authors agree that this article remains permanently open access under the terms of the Creative Commons Attribution License 4.0 International License

\begin{abstract}
The transformative power of economic policies in the European market increasingly brings into question the responsibility of business leaders about the effects of corporate activity on the social environment. Following the trend of achieving competitive advantage in the market and ensuring sustainable development through the production of sustainable social values, world business leaders apply the concept of social responsibility within the corporate governance. For the contemporary world, the approach represents a new model of economic democracy, whose political function is mirrored in their efforts to achieve sustainable development based on economic, environmental and social justice. The main focus of scientific interest is placed on the process of creating CSR policies determined by the EERI framework of Organizational performance as a process on organizational level and integration of CSR concept into organizational strategy. The research was conducted in 155 Macedonian companies from a deliberate target sample of companies. According to the principles of general methodology and specifics of the subject, the research was conducted on two levels: theoretical and empirical. The results of the research confirmed the significant influence of each of the dimensions of the organizational performance framework (EERI) on the process of creating CSR policies.
\end{abstract}

Keywords CSR Policy, Organizational Performance (OP), CSR Strategic Dimension, Social Shared Values

\section{Literature Review}

Social changes with an environmental and political dimension, which are the result of the intensity of globalization and liberalization, put in question and emphasize the responsibility of organizations to society. In the last three decades, intensive business development is influenced by pressure to generate profits, confronts global business leaders with the critical watchful eye of the public about their relationship and impact on social, ethical, economic and environmental aspects. In order to establish a balance between business activities and the care of internal and external stakeholders; organizations develop social responsible approach of action. Corporate social responsibility (CSR) is a complex multiform phenomenon, which by its nature is a kind of link between the business and social environment (with social, economic and environmental dimensions).

For the modern world, CSR represents a new model of economic democracy, whose political position is mirrored in their efforts to achieve sustainable development based on economic, environmental and social justice. EU companies promote their strategies for SR using their invasive instrumental value for sending signals to the stakeholders of the existence of social interest, as well as the return of investment in the future, based on a voluntary approach. The strategic approach to creating Social Responsible (SR) policies has a developmental dimension and leads to a long-term resolution of social problems and their origin, while addressing the reasons for it. It develops the human dimension of social organizations and creates conditions for equal opportunities for all.

The implementation of SR policies in organizations from developed countries leads to changes provided these policies are incorporated in organizational and business strategies with clearly defined and measurable objectives. These objectives should provide basis for a further step towards maintenance, ethical and competitive action. SR policies should be strategic and effective. Effective are those SR policies focused on results and that provide return on investment from $\mathrm{SR}$ initiatives (http://www.simplycsr.co.uk). Effectively created SR policies include actions in the areas that the organization has set as a priority in its strategy (1). The strategic SR policies are those policies that are part of the corporate 
strategy of the organization that earn double effect. Despite the achievement of strategic business objective, simultaneously reaching the good and benefit for the community. The strategic approach to the SR in corporate scenarios opens the possibility for innovative performance of the organization. In the development of the strategic approach, organizations are starting by their performance based on resources, due to the fact that they represent the origination source of competitive advantage and they are the driving force of any corporate strategy.

\subsection{Strategic Dimension of Creating Social Shared Values in 21 Century}

Throughout the long historical development of the concept, the classic view of the incompatibility with the free economy and the individual responsibility of the managers towards the stakeholders has been modernized and developed into a modern approach. According to the approach, the management acts within the moral and ethical responsibility, with interest to stakeholders and to additional shared values. In today's conditions, the synergy between business and the social environment, with the help of the concept of SR, enables the organization to sustain sustainable development. Thus, CSR becomes a fundamental requirement of modern management.

In the course of the historical development of social values, Porter \& Kramer (2) linked the role of SR in the development of competitiveness to the strategic approach to philanthropy. In the course of the new millennium, Porter \& Kramer (3) point out the moral obligation of organizations, sustainability, performance and reputation as the four most important factors that support and justify the strategic integrity of CSR in the organization's business operations. In the face of the needs of management, integrating the concept into an organization's activity is a wise way to provide a reason more for a competitive advantage on the market. For Porter \& Kramer (3), shifting towards strategically integrated SR in an organization implies mutual maturation of the organization and the social environment.

The dynamic nature of the concept is perceived through the evolution of market-based societies that move in the direction of mature capitalism. Social Value (SV) is much younger than economic value, but also more important to management. The battles of modern management in the 21 century lead to the reshaping of capitalism through the creation of social shared values (SSV). The concept of Porter \& Kramer (4) does not apply either to personal values or to "sharing" the created values from organization with the environment through the redistribution approach, but rather to the expansion of a set of economic and social values created through a partnership relationship of corporate systems with the environment. Porter (4) considers SSV as a new generation of capitalism, and says that "the involvement of social issues in strategy and operations is the next biggest transformation in managerial thinking" (5). The SSV provides long-term sustainability of the value chain, in spite of the short-term profits gained from the short-term relationship with the pressure from the external industrial environment. Creating an SSV is the driving force of a new wave of innovation in the value chain to develop productivity and efficiency within the global economy. The SSV concept also reflects the way in which organizations generate return on investment for shareholders / owners and stakeholders by creating long-term common values (values for stakeholders and wider society by addressing the root of social pain). The higher level of interaction between the business community and the social environment is due to the principle of creating a SSV. Any attempt to integrate CSR into the corporate strategy reminds management of the orientation towards the demands of the stakeholders of a social character and to the analysis of the resource-based OP. It contributes to linking the success of business to social progress. The power of strategic CSR is to release shared values that enhance the competitiveness of the organization. Investments in the social aspects of the competitive context for Porter \& Kramer (4) are a source of opportunities for creating SV.

\subsection{Contemporary Strategic Approaches in Creating Social Values}

The interest in CSR science is deeply focused on the issue of CSR strategy within the corporate strategy. This has an impact in the development of conceptual frameworks that describe the strategic process from a different aspect based on two dimensions: legitimacy and understanding/understanding of the organizational system (internal orientation) and the organizational environment (external orientation) in terms of acting through organizational and management processes and practices. When it comes to the applicability of the CSR Strategic Model, it has to be clear that the SR encompasses a wide range of social-oriented activities addressing social, environmental and other relevant aspects. SR activities express the ethical dimension of the organization and differ from the standard business/business activities (key processes) of the organization that have a central position and are with a purely profit orientation. For the provision of strategic dimension of the SR, management relies on the applicability of the following approaches:

a) The conceptual framework of Hanke \& Stark (6) illustrates the impact of the three interrelated strategic levels: corporate (organizational) culture, innovation and civil society and the four clusters (management system, leadership/commitment, responsibility and inter-ministerial connectivity) with internal and external orientation, under the influence of two driving forces, such as: legitimacy and sensemaking/sensegiving.

b) The Sharp \& Zaidman (7) approach for strategizing 
on CSR uses the theoretical and methodological framework of Jarzabkowski (8) called "strategy as a practice". They represent the penetration of the SR strategy in the business/activity of the organization through the migration from the traditional declarative strategy into an operational strategy of the organization. According to the model of Jarzabkowski (8), based on Mintzberg's thinking about the strategy, the strategy refers to activities oriented towards specific goals of the organization, and strategy refers to the process by which the strategy is integrated into organizational behavior and culture.

c) According O'Brien \& Robinson model of socially anchored competencies (SAC), the organization uses a new optical lens to identify market opportunities for creating socially responsible products/services and adding new values to existing products/services (9). A SAC is the title of the core competencies of an organization considered in terms of impact on stakeholders and the power to increase social benefits. Essential competencies of the organization are one set of abilities, skills and experiences that represent the collective learning of the organization. They are original and can not be easily repeated by competitors and are considered to be the root of the organization's competitiveness (10). At the same time, they are considered powerful instruments for innovation that maximize social and business benefits. The strategic alliance in the model refers to the cooperative mutual user relationship among several organizations, which enables development of new competences and gaining greater competitiveness. The most commonly used model of an alliance used by organizations is the template of an awarded grant for non-profit organizations for the implementation of social (social) projects. Another form of strategic alliance is certification (product/service license), shared human resources (volunteer activities for employees), community development projects, licensing, etc. (9). Business Benefit refers to increased production/productivity and profitability based on cost reductions; value added products/services, the development of the new product/service line and market competitiveness. Madique \& Ziger (11) and Kotler (12) studies point out a strong correlation between integrated teams with an innovative approach to development and product/service improvement (quoted in 9). The integration of the model in the organization provides a social benefit based on the strategic coherence of CSR programs and initiatives with a business strategy with the potential for producing social benefits. CSR programs are designed to use the capabilities and skills of the organization and contribute to its competitiveness.

At the operational level, the managerial approach to the strategic dimension of CSR is based on the Organizational Performance Model (OP). For Peter Drucker there are two inseparable dimensions of OP, efficiency and effectiveness, ie that there is no efficiency without effectiveness and vice versa. Jones \& George's approach (13) is a kind of continuation of Drucker's thinking, defining OP in highly functional organizations as a measure of how managers use the available resources efficiently and effectively to meet consumer /customer requirements and to achieve organizational goals. They indicate a proportional increase in OP by increasing efficiency and effectiveness.

Based on a series of theoretical and empirical perspectives Waheed et. al. (14) for the analysis of the multidimensional nature of the OP has proposed the EERI frame, which consists of four dimensions.

The degree of OP success depends on the simultaneous achievement of these four dimensions. In certain circumstances, the positive performance of a single dimension simultaneously results in a negative performance from another dimension (for example, the good OP of the dimension of resources follows the weaker performance of the other dimension, profitability). The goals and their achievement marked as effectiveness (E1) are considered the primary reasons for the existence of any organization. The organization exists to realize certain specific goals and is effective depending on the degree of their realization (14). The Efficiency (E2) is focused on the proper use of investments/resources. In this regard, Cherrington (15) and Kreitner \& Kinicki (16) stated that the organization has an excellent performance if it provides all the necessary factors for production or for the use of the environment by providing valuable resources. According to Mitchell (17), the Relevance (R) denotes the degree to which stakeholders consider the organization to be relevant to their needs and is associated with the demand for products/services of the organization, implies stakeholder orientation and satisfaction (14) (16). The OP is also determined by the ability to map critical stakeholders, identify their preferences (needs, interests) and the approach to meeting their needs. Innovation/Creativity (S) are essentially distinguished by a change, for Seng and et al. (18) and Lusthaus et al. (19), the survival of the organization depends on its aspiration to the best continuous adaptation in the changing environment and to the development needs of its stakeholders. Organizational creativity refers to the extent to which innovation in the design of organizational policy and creativity in addressing the problem exists (14). The essential concept related to innovation is the creation of values, whether the values created are expressed in the form of financial parameters or social benefits.

The proposed models that measure the OP are focused on the degree of accomplished goals (effectiveness), through the degree of optimal utilization of the invested resources (efficiency) or with a focus on internal organizational processes. It is obvious that the researchers face difficulties in determining the sum constitutional elements that are valid for the assessment of the OP. One and/or two constitutional dimensions of the OP (eg. efficiency and effectiveness) are not sufficiently representative of themselves for a comprehensive 
assessment of the OP. Another problem is that each of the offered OP evaluation models does not cover all aspects and functions of the organization.

\subsection{Organizational Performance}

The studies of Hong \& Jeong (20) and Oritz \& Kuhne (21) link the development of responsibility to the organization's action and sustainable development with the four dimensions that were regarded as the dimensions of the OP by their origin: 1. Efficiency: development of cost to improve opportunities (for example, a program for pollution prevention to prevent possible pollution costs); 2 . Coordination: development of the ability to coordinate in the network of suppliers in order to improve productivity and flexibility (eg. a collaborative approach to reducing pollution); 3. Co-operation: development of market opportunities and capabilities for developing products/services that are appropriate to market needs to overcome a relatively weak negotiating position (eg: introducing policies for systematic auditing of stakeholders to gain competitiveness based on provided products/services relevant to the needs of the stakeholders); 4. Innovation: development of innovation capabilities in charge of responsibility for influencing the development of excellent new products/services.

$\mathrm{H}$ : The process of creating SR policies is conditioned by the constitutional dimensions of the OP (EERI framework).

\section{Methodology}

\subsection{Research Approach and Instrument}

For the purposes of the research (identifying the potential impact of factors of organizational origin - OP on the creation of CSR policies), we applied a research strategy for exploratory research with a deductive approach.

The survey was conducted on a purposeful (target) sample of respondents, i.e. 155 Macedonian corporate systems (87 private companies and 68 state institutions) from total population of 237 companies registered in period of 7 years for annual CSR prize.

In order to collect the necessary empirical data, the method of survey with the research instrument questionnaire was used with closed type of questions. The questionnaire consists of two subscales: 1) creating CSR policies, 2) OP. Respondents of the claims of the two general categories expressed the degree of their agreement with each claim on the five-level Likert scale. The Socially Responsible Politics subcategory covers 36 claims, for four aspects: CSR strategy, stakeholder engagement, CSR management, and performance management. The organizational performance subcategories includes claims for assessing the OP in relation to the EERI framework
(Effectiveness, Efficiency, Relevance and Innovation).

The obtained value of coefficient $\alpha(\alpha=0.9577)$ for the measuring instrument of 55 assertions as a whole indicates its excellent internal consistency. With a deeper analysis of the internal consistency of each subgroup of questions from the subscales of the questionnaire, Table 1 shows the values obtained for coefficient $\alpha$ indicating the following:

Table 1. The value of the crown alpha coefficient $(\alpha)$ for each subscale individually

\begin{tabular}{|c|c|c|}
\hline & $\alpha$ Values & Interpretation \\
\hline $\begin{array}{l}\text { Internal consistency of } \\
\text { the questionnaire }\end{array}$ & 0.9577 & $\begin{array}{c}\text { Excellent internal } \\
\text { consistency }\end{array}$ \\
\hline Subscale & \multicolumn{2}{|c|}{ Process of creating CSR policy } \\
\hline Strategy & 0.9119 & $\begin{array}{c}\text { Excellent internal } \\
\text { consistency }\end{array}$ \\
\hline $\begin{array}{l}\text { Interaction with } \\
\text { stakeholders }\end{array}$ & 0.8121 & $\begin{array}{c}\text { Acceptable internal } \\
\text { consistency }\end{array}$ \\
\hline Management & 0.8121 & \multirow{2}{*}{$\begin{array}{l}\text { Good internal } \\
\text { consistency }\end{array}$} \\
\hline $\begin{array}{l}\text { Performance } \\
\text { management }\end{array}$ & 0.7836 & \\
\hline Subscale & \multicolumn{2}{|c|}{ Organizational performance } \\
\hline Effectiveness (E1) & 0.8924 & \multirow{4}{*}{$\begin{array}{l}\text { Good internal } \\
\text { consistency }\end{array}$} \\
\hline Efficiency (E2) & 0.7719 & \\
\hline Relevance (R) & 0.8293 & \\
\hline Innovation (I) & 0.8587 & \\
\hline
\end{tabular}

\section{Statistical Analyses and Results}

The process of creating SR policies at the organizational level is analyzed according to the indicator of the level of development of each of the four aspects of the process individually, which can be (weak practice / without records, in development and good practice).

The confirmation (or rejection) of the hypotheses, or the analysis of the effect of a multiple independent variable (predictor) on the dependent variable (outcome / result), was determined by applying appropriate statistical procedures and techniques characteristic of the bivariate and multivariate level of analysis. These procedures are taken into account according to the nature of the measurements of the variables such as: crosstabulations, independent sample $\mathrm{T}$ - test, bivariate correlation and linear regression analysis, whereby the accepted level of significance is $p<0.05$ and / or $p<0.01$, i.e. it can be said that the results obtained are generalized and are valid for $95 \%$ and / or $99 \%$ of the surveyed population.

For the input, processing and interpretation of the empirical data obtained from the research, the SPSS program (Statistical Pascage for Social Science) is applied.

\subsection{Developmental Level of Aspects of the Process of Creating CSR Policies in Public and the Private Sector Organizations}

From the graphic illustration (Figure 1) demonstrating 
the percentage difference between the organizations pertaining to the public and the private sector according to the level of development of each of the four aspects partaking the process of creating the CSR policies, the following is noted:

- $\quad 49.42 \%$ of private sector organizations and $32.35 \%$ of those in the public sector have determined that the aspect of the CSR strategy is in development. The results highlighted that $39.08 \%$ of private sector organizations have a positive trend to develop the aspect as a good practice, while in $45.58 \%$ of public sector organizations the aspect is poorly developed or without record;

- $\quad$ Private and public sector organizations, with a small percentage difference (52.87\% and 57.35\%), during the process of creating the CSR policies show the development stage of the aspect of interaction with the stakeholders. Statistical evidence about $32.18 \%$ of private sector organizations and $26.47 \%$ of public sector organizations show a positive trend in developing the aspect of good practice;

- $60.29 \%$ of public sector organizations and $48.27 \%$ of private sector organizations show the development of the governance aspect. Statistical dates about $42.53 \%$ of private sector organizations show the application of the aspect as good practice, compared with $27.94 \%$ of public sector organizations that show poor development of the aspect;
- Regarding the performance management aspect (results), public sector organizations register a better level of development, i.e. $57.65 \%$ of them show the development of the aspect, compared to $54.09 \%$ of private sector organizations. Private sector organizations, $35.42 \%$, show a positive trend in developing the aspect of good practice.

Figure 1 shows the percentage distribution of organizations from the private and public sector in terms of the level of development of each of the four aspects of the process of creating the SR policies

By applying the Pearson correlation coefficient (r), the existence of a connection between the process of creating the SR policies and OP was tested, whereby the obtained moderate and positive value of the coefficient, with two-way testing of the relationship, indicates a statistically significant, moderate collar, positive relationship between the process of creating the SR policies and the OP $(\mathrm{r}=.47$, $\mathrm{N}=155, \mathrm{p}<.01$ ) (Table 2).

Linear regression analysis is applied in order to determine the extent and direction of the influence of the predictors / antecedents - OP on the process of creating the CSR policies.

Table 3 summarizes the descriptive statistics and the results of the analysis that clearly indicate the statistically significant influence of the predictor, in the case of OP on the process of creating the SR policies, with statistical significance at the level of $0.05(\mathrm{p}<.05)$.

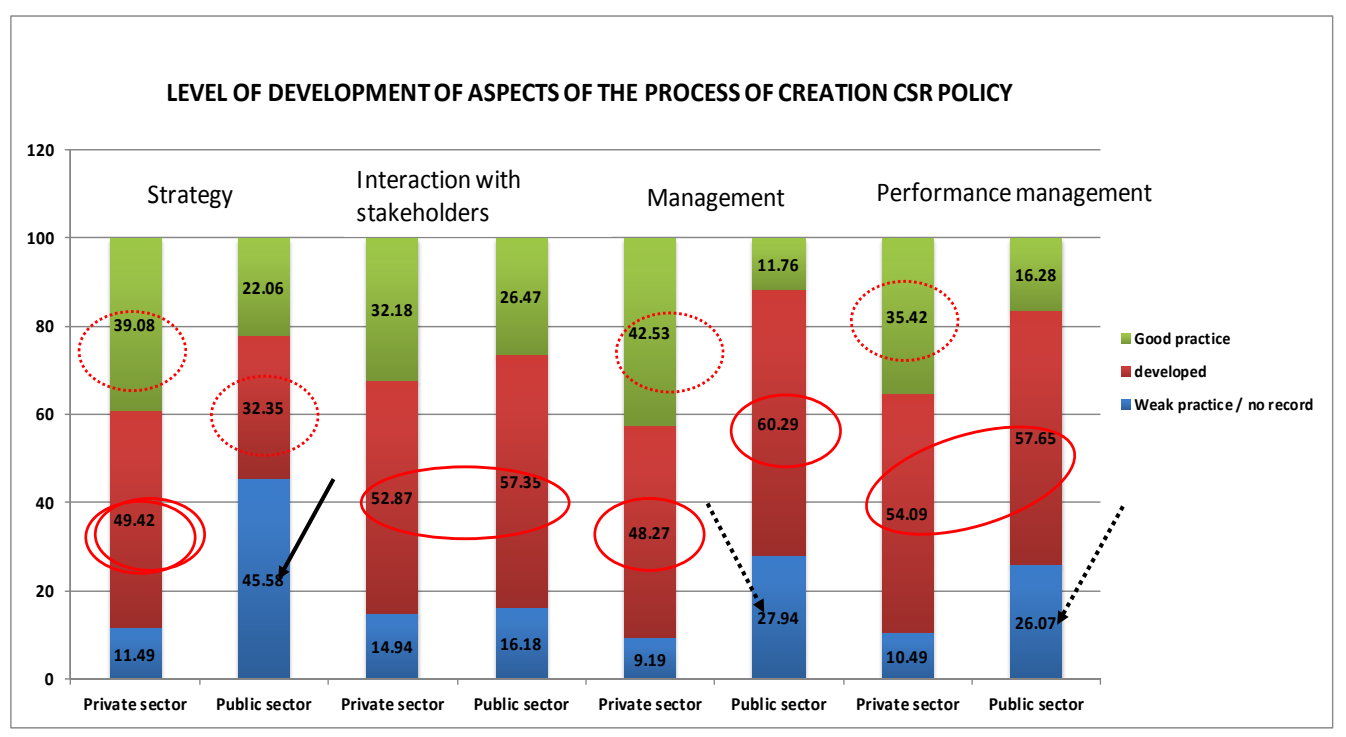

Figure 1. Comparison of organizations pertaining to the private and public sector regarding the level of development of the aspects partaking in the process of creating the CSR policy 
Table 2. Bivariate correlation between the process of creating the SR policies and OP

\begin{tabular}{|c|c|c|c|}
\hline \multicolumn{4}{|c|}{ Correlations } \\
\hline & & OP total & CSR total \\
\hline \multirow{3}{*}{$\mathrm{OP}$} & Pearson Correlation & 1 &, $470(* *)$ \\
\hline & Sig. (2-tailed) & , &, 000 \\
\hline & $\mathrm{N}$ & 155 & 155 \\
\hline \multirow{3}{*}{ CSR } & Pearson Correlation &, $470(* *)$ & 1 \\
\hline & Sig. (2-tailed) &, 000 & , \\
\hline & $\mathrm{N}$ & 155 & 155 \\
\hline
\end{tabular}

Table 3. Regressive analysis of the predictive impact of OP on the process of creating CSR policies

\begin{tabular}{|c|c|c|c|c|}
\hline \multicolumn{7}{|c|}{ Model Summary(b) } \\
\hline Model & $\mathrm{R}$ & R Square & Adjusted R Square & $\begin{array}{c}\text { Std. Error of the } \\
\text { Estimate }\end{array}$ \\
\hline 1 &, $470(\mathrm{a})$ &, 221 &, 216 &, 65081 \\
\hline a Predictors: (Constant), OPtotal & & \\
\hline b Dependent Variable: CSR total
\end{tabular}

\begin{tabular}{|c|c|c|c|c|c|c|}
\hline \multicolumn{7}{|c|}{ ANOVA(b) } \\
\hline \multicolumn{2}{|c|}{ Model } & Sum of Squares & df & Mean Square & $\mathrm{F}$ & Sig. \\
\hline \multirow{3}{*}{1} & Regression & 18,346 & 1 & 18,346 & 43,316 &, $000(a)$ \\
\hline & Residual & 64,803 & 153 &, 424 & & \\
\hline & Total & 83,150 & 154 & & & \\
\hline \multicolumn{7}{|c|}{ a Predictors: (Constant), OPtotal } \\
\hline \multicolumn{7}{|c|}{ b Dependent Variable: CSR total } \\
\hline
\end{tabular}

\begin{tabular}{|c|c|c|c|c|c|c|}
\hline \multicolumn{7}{|c|}{ Coefficients(a) } \\
\hline & & \multicolumn{2}{|c|}{ Unstandardized Coefficients } & \multirow{2}{*}{$\frac{\text { Standardized Coefficients }}{\text { Beta }}$} & \multirow{2}{*}{$\mathrm{t}$} & \multirow{2}{*}{ Sig. } \\
\hline \multicolumn{2}{|r|}{ Model } & B & Std. Error & & & \\
\hline \multirow{2}{*}{1} & (Constant) & 1,546 &, 260 & & 5,938 & ,000 \\
\hline & OPtotal & 473 & ,072 & ,470 & 6,581 &, $000 *$ \\
\hline \multicolumn{7}{|c|}{ a Dependent Variable: CSR total } \\
\hline \multicolumn{7}{|c|}{${ }^{*}$ significant at the 0.05 level } \\
\hline \multicolumn{7}{|c|}{$* *$ significant at the 0.01 level } \\
\hline
\end{tabular}

The statistical parameters of the bivariate correlation for the relationship of each of the constitutional dimensions of the OP (elements of the EERI framework) to each of the aspects of the process of creating the SR policies (strategy, stakeholder interaction, management and management of results) shown in Table 4, indicate (from weak to moderate) positive correlation, two-way tested and statistically significant at the level of 0.01 . 
The obtained results from the regression analysis to determine the impact of each of the constitutional dimensions of OP on the process of creating CSR policies, as a continuation of the previous statistical method for determining the bivariate correlation, indicate the following (Table 5):

- $\quad$ statistically significant impact on the $\mathrm{E} 1$ dimension of the OP framework for the process of creating CSR policies according to the statistic values $[(\mathrm{F}(1,154)=25,483 ; \mathrm{t}=5,048$; $\mathrm{p}=.000($ Sig. $=.000)]$ with a statistical significance of $95 \%(\mathrm{p}<.05)$;

- according to the values $[(\mathrm{F}(1,154)=41,878 ; \mathrm{t}=6,471 ; \mathrm{p}=.000(\mathrm{Sig} .=.000)]$, which relate to the impact of the E2 dimension of the OP framework on the process of creating the SR policies, the statistically significant conditionality of the process of creating the SR policies from the constitutional dimension E2 of the OP at the level $p<.05$ has been established;

- the parameters $[(\mathrm{F}(1,154)=39,328 ; \mathrm{t}=6,271 ; \mathrm{p}=.000(\mathrm{Sig} .=.000)]$ indicate a statistically significant conditionality of the process of creating SR policies from the dimension $\mathrm{R}$ of the OP $(\mathrm{p}<05)$;

- three statistical values $[(\mathrm{F}(1,154)=36,911 ; \mathrm{t}=6,075 ; \mathrm{p}=.000(\mathrm{Sig} .=.000)]$ that relate to the impact of the I dimension of the OP framework on the process of the creation of SR policies, indicate a statistically significant influence on the dependent variable at the statistical level of significance $\mathrm{p}<.05$.

\subsection{Process of Creating SR Policies Conditioned by the Constitutional Dimensions of the OP}

Regarding the impact of each of the four constitutional dimensions of the OP (Dimensions of the EERI Framework) on the process of creating the SR policies (Table 4), the obtained statistical parameters for the Pearson correlation coefficient and the statistical significance of bivariate correlation indicate a positive linear relationship between the process of creating the SR policies and the constitutional dimensions of the OP, with a 99\% interval of security for the impact ie statistical significance at level .01 ( $p<.01$ ).

Table 4. Bivariate correlation between the constitutional dimensions of the OP and the process of creating the SR policies

\begin{tabular}{|c|c|c|c|c|c|c|c|c|c|c|c|}
\hline & & \multirow{2}{*}{ E1 } & \multirow{2}{*}{ E2 } & \multirow{2}{*}{$\mathrm{R}$} & \multirow{2}{*}{ I } & \multirow{2}{*}{ OPtotal } & \multirow{2}{*}{ Strategy } & Stakeholders & \multirow{2}{*}{ management } & Performance & \multirow{2}{*}{ CSRtotal } \\
\hline & & & & & & & & interaction & & management & \\
\hline \multirow{3}{*}{ E1 } & Pearson Correlation & 1 &, $852(* *)$ &, $815(* *)$ &, $724(* *)$ &, $909(* *)$ &, $408(* *)$ &, $290(* *)$ &, $382(* *)$ &, $320(* *)$ &, $378(* *)$ \\
\hline & Sig. (2-tailed) & , &, 000 &, 000 &, 000 &, 000 &, 000 &, 000 &, 000 &, 000 &, 000 \\
\hline & $\mathrm{N}$ & 155 & 155 & 155 & 155 & 155 & 155 & 155 & 155 & 155 & 155 \\
\hline \multirow{3}{*}{ E2 } & Pearson Correlation &, $852(* *)$ & 1 &, $852(* *)$ &, $784(* *)$ &, $940(* *)$ &, $485(* *)$ &, $355(* *)$ &, $487(* *)$ &, $389(* *)$ &, $464(* *)$ \\
\hline & Sig. (2-tailed) &, 000 & , &, 000 &, 000 &, 000 &, 000 &, 000 &, 000 &, 000 &, 000 \\
\hline & $\mathrm{N}$ & 155 & 155 & 155 & 155 & 155 & 155 & 155 & 155 & 155 & 155 \\
\hline \multirow{3}{*}{$\mathrm{R}$} & Pearson Correlation &, $815(* *)$ &, $852(* *)$ & 1 &, $831(* *)$ &, $943(* *)$ &, $476(* *)$ & ,316(**) &, $485(* *)$ & ,399(**) & ,452(**) \\
\hline & Sig. (2-tailed) &, 000 &, 000 & , &, 000 &, 000 &, 000 &, 000 &, 000 &, 000 &, 000 \\
\hline & $\mathrm{N}$ & 155 & 155 & 155 & 155 & 155 & 155 & 155 & 155 & 155 & 155 \\
\hline \multirow{3}{*}{ I } & Pearson Correlation &, $724(* *)$ &, $784(* *)$ &, $831(* *)$ & 1 & ,911(**) & ,473(**) &, $340(* *)$ &, $474(* *)$ &, $345(* *)$ &, $441(* *)$ \\
\hline & Sig. (2-tailed) &, 000 &, 000 &, 000 & , &, 000 &, 000 &, 000 &, 000 &, 000 &, 000 \\
\hline & $\mathrm{N}$ & 155 & 155 & 155 & 155 & 155 & 155 & 155 & 155 & 155 & 155 \\
\hline \multirow{3}{*}{ OPtotal } & Pearson Correlation &, $909(* *)$ &, $940(* *)$ &, $943(* *)$ &, $911(* *)$ & 1 &, $499(* *)$ &, $353(* *)$ &, $495(* *)$ &, $392(* *)$ &, $470(* *)$ \\
\hline & Sig. (2-tailed) &, 000 &, 000 &, 000 &, 000 & , &, 000 &, 000 &, 000 &, 000 &, 000 \\
\hline & $\mathrm{N}$ & 155 & 155 & 155 & 155 & 155 & 155 & 155 & 155 & 155 & 155 \\
\hline
\end{tabular}

** Correlation is significant at the 0.01 level (2-tailed). 
Table 5. Regressive analysis of the predictive impact of each dimension of OP on the process of creating CSR policies

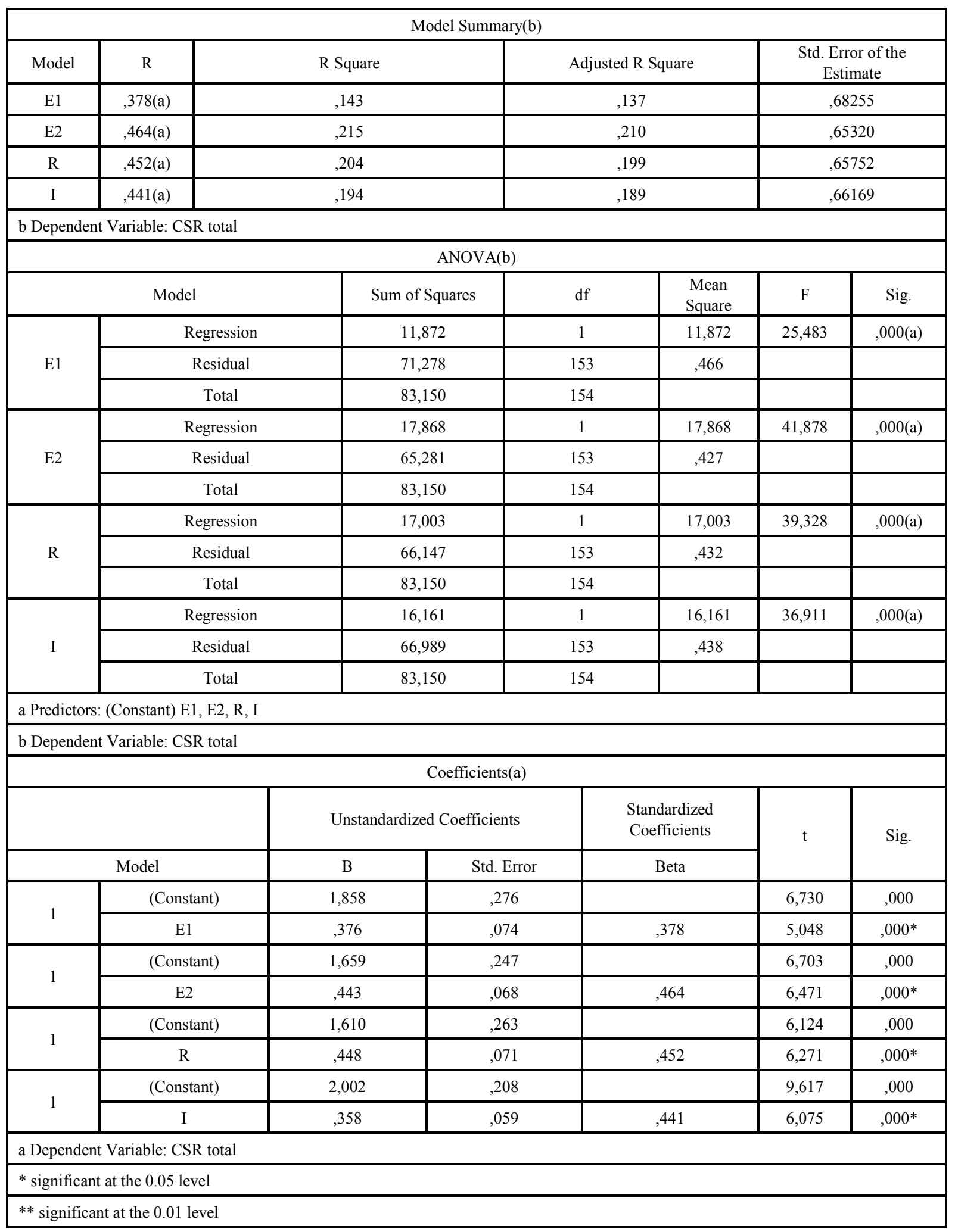




\section{Organizational Performance and Creation of Social Shared Values}

The influence of the OP on the social environment depends on the degree of social cohesion that corresponds to the concept of shared values.

The views of Levitt's agency theory; Freeman theory of stakeholders; Barney`s theory of firm based on resources and the Waddock and Graves hypothesis for weakness of resources are in favor of the relationship between CSR and the financial performance of the organization through the dimension of creating social values.

Namely, the creation of values is considered the heart of the OP when it is defined through the resources involved in the process. For Barney (22), Branco and Rodingues (23), the organization gains benefits from its unique, original resources that meet the criteria of the view. CSR allows the organization to build its own original resources, such as reputation, capabilities, knowledge, and a network of relationships. Oliver (24) defined the strategic use of CSR through the perspectives of institutional theory and resource-based theory as a tool for achieving organizational sustainability. The organization generates a competitive advantage by effectively managing its own resources and abilities, which are valuable, rare, unrepeatable and irreplaceable, while CSR improves competitive advantage by helping to create and manage specific resources and capabilities (1). For Branco and Rodrigues (23), investment in SR policies develops new resources and capabilities of the organization that are related to know-how knowledge and organizational culture which are the internal benefit of the organization from the SR investment. The external benefit according to this viewpoint is found in the reputation of the organization.

Creation of values is considered a situational process if one takes into account: the different concept of evaluating the results of organizations with different activities; performance based on different dimensions (eg, profitability, innovation, efficiency and effectiveness); the significance of the value created with the performance for different users/stakeholders and investors. Values generated by the OP can be tangible, intangible, operational and financial. The literature points to the tendency to create shared values as the ultimate goal of organizations, primarily those of the public sector (Porter (25), Bichta (26) Filho et. al (27)).

Regarding the strategic point of view, strategizing the concept on organizational level depends on the success rate of the overall OP, as well as from the micro practices that are used to integrate the concept of CSR in organizational strategy and the relationship between micro-practices and institutional work that contributes to increase the legitimacy of the SR in the organization. According to a resource-based theory, the in-house of the organization and the competitive environment are the two key factors that shape the organizational/corporate strategy and the OP.
Hence, the interaction between the OP and the strategic form of the SR shape the organizational capabilities and organizational competitiveness.

The theoretical justification for integration of the SR with the organizational strategy and stakeholder satisfaction is explained in Porter's theory of competitiveness, the organization resource-based theory and Freedman's stakeholders' theory for strategic management (28). As Hart and Sharma (29) say, contemporary stakeholder management is based either on resources or on moral arguments to achieve cost savings, differentiation from rivals or legitimacy of the activity.

The results of the survey confirmed the influence of the OP on the process of creating the CSR policies, as well as the impact of the constitutional dimensions of the OP (EERI framework) on each of the four aspects of the process of creating the CSR policies (CSR strategy, interaction with the stakeholders, management and Performance management of the SR).

In the survey, the OP assessment was made through constitutional dimensions, which are non-material (non-financial) operational dimensions of the OP according their nature and which relate to: integration of goals (effectiveness-E1); integration of internal processes, rational allocation of resources and their attributes (efficiency -E2); satisfaction of the stakeholders of suitably designed products / services, their availability to all stakeholders (relevance-R) and innovative organizational culture towards the organization's interior and its external environment (innovation-I). For Sangle (30), the success of the SR depends on the ability of the organization to: 1) integrates the CSR strategy into other functional strategies; 2) to manage the different stakeholder groups; 3 ) evaluate the benefits of SR and 4) provide managerial support for process management.

According to the conceptual framework for the strategization on SR of Hanke \& Swank Strategic model (31), the model of SAC and the Jarzabkowski framework for the SR strategy (8), the results of the survey determine the significant impact of the constitutional dimensions of the OP on aspects from the process of creating the CSR policies, which are considered antecedents/predictors of the strategic approach to the CSR. According to the framework of Jarzabkowski, the dimensions of the OP influence the interaction of the following elements of the model: management, organizational context and targeted activities. The process of creating SR policies is reviewed through the synergistic relationship between the OP and the concept of SR built from the potential, attributes, competencies of organizational resources, stakeholder management and positive management practices that produce positive cognitive, emotional and social behavior among employees (commitment, personal prosperity, job satisfaction, better cognitive functioning and decision-making, creativity, initiative, etc.) and contribute to the development of a positive working environment and, 
organizational climate, organizational communication and creating socio-organizational social capital (positive relationships and interactions between employees). Such a link generates added value to the organization and can be understood as one continuum that is in function of the interests of the internal and external groups of stakeholders of the organization. The process of strategizing the concept of SR in the organization is perceived in the perspective of institutional micro-practices engaged in the process of integrating SR in organizational key processes and in organizational strategy.

Hence, an integrative, holistic approach to the development of SR dimensions, through the interplay of strategic policies, management support and practices and the non-material (operational) dimensions of the OP is of organizational and strategic interest. The strategic status of the SR is enhanced by mobilizing institutional micro-practices and policies that are part of the organizational culture and which are in mutual interaction and support the institutional and practical aspect of the strategic organization of the SR. Stainer (32) calls the organization's inclusiveness and competitiveness synchronized generators of its survival, development and performance excellence.

\section{Conclusions}

The strategy for CSR is a reflection of the organizational sensitivity on a series of social, environmental and economic pressures. Organizations use the strategy as an instrument by which they send signals denoting their social interest to different stakeholder groups, which are not always related to the organization's core processes. In developing the strategic approach to the SR, organizations rely on their own resource-based performance, because they consider them the starting source of competitive advantage and the main drivers of each strategy.

Considering the fact that the process of strategizing as a concept has two faces, institutional, through which the concept is designed in a strategy, and operational from the aspect of the design of the strategy and policy for the SR, it is inevitable to have in mind the three basic aspects of the institutional work: the organizational culture (the system of values, the internal identity of the organization), organizational policy (the legal aspects of acting, negotiation, etc.) and operating procedures (working framework, standardization of work processes). From a practical point of view, the strategic process refers to the micro practices used by managers in the strategic approach to the concept. The development of these micro practices contributes to the development of the concept on a micro level. In addition, we take into account the impact of micro practices that support the two driving forces, the legitimacy of SR and sensemaking/sensegiving, found in the conceptual framework of Hanke \& Swank (33).
Micromanagement practices support the process by which managers are devised, and employees recognize the process of integration of the SR into the organizational strategy.

\section{REFERENCES}

[1] McWilliams, A., Donalds, S., Wright, P., (2006) Introduction Corporate social responsibility Strategic Implications., Journal of management studies 43:1

[2] Porter, M. E. and M. R. Kramer: (2002). 'The Competitive Advantage of Corporate Philanthropy', Harvard Business Review

[3] Porter, M. and M. Kramer: 2006, «Strategy \& Society', Harvard Business Review 84(12), 78-92

[4] Porter, Michael E., and Mark R. Kramer. "Creating Shared Value." Harvard Business Review 89, nos. 1-2 (JanuaryFebruary 2011): 62-77

[5] Forbes, 2014, http://www.forbes.com/sites/csr/2012/06/04/ what-is-creating-shared-value/

[6] Hanke, T., Stark, W. (2009) Strategy Development: Conceptual Framework on Corporate Social Responsibility. Journal of Business Ethics, 85, pp:507-516

[7] Sharp, Z., Zaidman, N. (2010) Strategization of CSR. Journal of Business Ethics 93, pp:51-71

[8] Jarzabkowski, P.: 2005, Strategy as Practice - An Activity Based Approach (Sage, London).

[9] O`Brien, D. \& Robinson, M. J. (2001) Integrating Corporate Social Responsibility with Competitive Strategy. Center for corporate citizenship at Boston College

[10] Porter, M. (1990), Competitive Advantage: Creating and Sustaining Superior Performance, Free Press,New York, NY

[11] Maidique.M.A.. and B.I. Zirga (1984). 'A Study of Success and Failure in product innovation: The Case of the U.S. Electronic Industry'. IEEE Transaction Engineering management EM 31-4, 192-203

[12] Philip Kotler, Nancy Lee (2005): Corporate Social Responsibility, Doing the most Good for Your

[13] Jones, R. G., \& George, M. J. (2008) Contemporary management. Global communication

[14] Waheed, A., MAnsor, N., Ismail, N. A. (2010). Assessing Performance of Public Sector Organizations: A Theoretical Framework. Interdisciplinary journal ofcontemporary research in business, Vol.2 No 8,pp 329-349

[15] Cherrington, D. J. (1989). Organizational Behaviour: The Management of Individual and Organizational Performance. Boston: Allyn and Bacon

[16] Kreitner, R., \& Kinicki, A. (2004). Organizational Behavior. New York: McGraw-Hill / Irwin

[17] Michael Hopkins (2011) A Planetary Bargain: Corporate Social Responsibility Comes of Age (MacMillian, UK, 1998 
accessible on http://www.mhcinternational.com/articles/def inition-of-csr)

[18] Senge, P. , Kleiner, A., Roberts, C., Ross, R., Roth, G., \& Smith, B. (1999). The dance of change: The challenges to sustaining momentum in learning organizations. New York: Doubleday

[19] Lusthaus, C., Adrien, M. H., Anderson, G., Carden, F., \& Montalvan, G. P. (2002). Organizational Assessment: A Framework for Improving Performance. Ottawa: International Development Research Centre / Inter American Development Bank

[20] Hong, P. and Jeong, J.: (2006), Supply chain management practices of SMEs: from a business growth perspective, Journal of Enterprise Information Management, 19(3), 292302

[21] Oritz, A. D. \& Kuhne, S. (2008) Implementing Responsible Business Behavior from a Strategic Management Perspective: Developing a Framework for Austrian SMEs. Journal of Business Ethics Volume 82, Issue 2, pp 463-475

[22] Barney, J. (1991) Firm resource and sustained competitive advantage. Journal of Management 17(1): 99-120.

[23] Branco, M. and Rodrigues, L. (2006) Corporate social responsibility and resource-based perspectives. Journal of Business Ethics 69(2): 111-132

[24] Oliver, C. (1997) Sustainable competitive advantage: Combining institutional and resource-based views. Strategic Management Journal 18(9): 697-713.

[25] Porter, M. (1980), Competitive Strategy, Free Press, New York, NY.

[26] Bichta, C., (2003) Corporate social responsibility A Role in Government policy and regulation? University of BATH School of management, UK

[27] Filho, M. J., Wandrley, L., Gomez, C., Farache, F. (2010) Strategic Corporate Social Responsibility Management for Competitive Advantage. BAR, Curitiba, v.7 n.3, art5, pp.294-309, July/ September, 2010

[28] Friedman, M. (1970), The Social Responsibility of Business is to Increase its Profits, The New York Times Magazine

[29] Hart, S. L., \& Sharma, S. 2004. Engaging fringe stakeholders for competitive imagination. Academy of Management Executive, 18: 7-18.

[30] Sangle, S (2010) Critical success factors for corporate social responsibility: a public sector perspective. Corporate Social Responsibility, Volume 17 No10 July/August

[31] Hanke, T. and W. Stark: (2005), “Companies' 'Good Reasons' to Invest in Corporate Social Responsibility', in Proceedings of ISC - International Sustainability Conference (Universita“t Basel).

[32] Stainer, L (2006). Performance management and corporate social responsibility: the strategic connection. Briefing in Entrepreneurial Finance, Volume 15 No 5, pp 253-264

[33] Hanke, T., Stark, W. (2009) Strategy Development: Conceptual Framework on Corporate Social Responsibility. Journal of Business Ethics, 85, pp:507-516 